\title{
Operational budgeting using fuzzy goal programming
}

\author{
Saeed Mohammadi", Kamran Feizi and Ali Khatami Firouz Abadi
}

Department of Management, Allameh Tabatabaie University, Tehran, Iran

\begin{tabular}{l}
\hline C H R O N I C L E \\
\hline Article history: \\
Received May 22, 2013 \\
Received in revised format \\
12 August 2013 \\
Accepted 7 September 2013 \\
Available online \\
September 12 2013 \\
\hline Keywords: \\
Operational budgeting \\
Fuzzy goal programming \\
Uncertainty
\end{tabular}

\section{A B S T R A C T}

\begin{abstract}
Having an efficient budget normally has different advantages such as measuring the performance of various organizations, setting appropriate targets and promoting managers based on their achievements. However, any budgeting planning requires prediction of different cost components. There are various methods for budgeting planning such as incremental budgeting, program budgeting, zero based budgeting and performance budgeting. In this paper, we present a fuzzy goal programming to estimate operational budget. The proposed model uses fuzzy triangular as well as interval number to estimate budgeting expenses. The proposed study of this paper is implemented for a real-world case study in province of Qom, Iran and the results are analyzed.
\end{abstract}

\section{Introduction}

One of the primary concerns among most governmental agencies is to have appropriate budget approved as early as the beginning of each fiscal year. A good operating budget motivates managers to do their best to reach their objectives while an inappropriate budget could virtually hurt managers' motivations. There are many studies for budgeting planning by considering different objectives, which may often be in conflict. Guilding (2003) performed an empirical survey and reported that capital budgeting systems in hotels operating under a divorced owner/operator structure could provide more formalization and a bigger propensity for investment proposal cash forecast biasing. Zhang et al. (2011) discussed the multinational capital budgeting problem to choose appropriate project where there were some candidate foreign projects. In their work, special cash flows and value sources of foreign projects were investigated. The work proposed one new uncertain zero-one integer model for optimal multinational project selection and to handle the resulted problem, a hybrid intelligent algorithm integrating the 99 Methods and genetic algorithm was provided. Libby and Lindsay (2010) presented the results of two surveys of mid- to large-sized North-American organizations to update the literature on North-American budgeting practices, to collect empirical 
evidence to evaluate the criticisms, and to start to detect strong tendencies or patterns in budgeting practice to inform future academic research. They reported that the majority of companies that budgets continue to apply for control purposes. Roper and Ruckes (2012) analyzed the optimal capital budgeting mechanism when divisional managers were privately informed about the arrival of future investment projects. Uyar and Bilgin (2011) explored budgeting practices of Turkish hotels in the Antalya region and reported that having a budget committee and budget manual are common for Turkish hotels. Kalu (1999) presented an extended goal programming methodology to describe the problem of capital budgeting under uncertainty to overcome the defects of chance-constrained capital budgeting models. More specifically, since financial planners frequently deal with the complex problem of capital budgeting by aggregating large numbers of small investment proposals into families of large projects, Kalu (1999) presented necessary and sufficient conditions for the acceptance of a set of investment projects by a business enterprise. The author indicated that under uncertainty, firms could face with capital rationing were less economically efficient than others. The author also reported that optimal allocation policy under uncertainty needs the actual discount rate to be bigger than the market cost of capital, a finding which is consistent with corporate finance practice. Bourmistrov and Kaarbøe (2013) explored how change in the design principles of management control systems (MCSs) based on using the beyond budgeting (BB) ideas has impacted the transition of decision-makers from "comfort" to "stretch" zones and how this transition changed the supply of and demand for managerial information. They explained how the implementation of new information provided by the MCS design, which is based on new principles, move decisionmakers into the "stretch zone" characterized by new characteristics of decision-makers' mindset and behavior.

\section{The proposed model}

In this paper, we present a mathematical model based on fuzzy goal programming (Ignizio, 1976; Lee, 1972) for operational budgeting planning. Goal programming is one of the most popular techniques for handling various objectives in different levels. In goal programming, there are two kinds of constraints of hard and soft. The hard constraints are the same as the traditional constraints used in linear programming where the equality constraints must be satisfied and the inequality constraints are handled using slack/surplus variables. The soft constrains are other groups of constraints where we allow some deviation either positively or negatively. Any soft constraint must be handled using two variables of positive $\left(d_{i}^{+}\right)$and negative deviations $\left(d_{i}^{-}\right)$. These two constraints are normally considered in the objective functions and the primary goal is to optimize deviation from desirable value.

\subsection{Fuzzy programming}

Zimmermann (1978) is believed to be one of the pioneers to develop fuzzy programming for the following mathematical programming,

$\min Z(x)=\left[z_{1}(x), \cdots, z_{k}(x)\right]$

subject to

$g_{i}(x) \leq b_{i}, i=1, \cdots, m$

$x \geq 0$.

In order to solve this problem, we use the following steps,

Step 1. Solve model (1) $k$ different times where each time by considering one objective each time.

Step 2. Setup the following ideal matrix based on $k$ different solutions obtained from Step 1. 


\section{Table 1}

Productivity matrix

\begin{tabular}{ccccc}
\hline & $Z_{1}(x)$ & $Z_{2}(x)$ & $\cdots$ & $Z_{k}(x)$ \\
\hline$x^{1}$ & $Z_{1}^{*}\left(x^{1}\right)$ & $Z_{2}^{*}\left(x^{1}\right)$ & $\cdots$ & $Z_{k}^{*}\left(x^{1}\right)$ \\
$x^{2}$ & $Z_{1}^{*}\left(x^{2}\right)$ & $Z_{2}^{*}\left(x^{2}\right)$ & $\cdots$ & $Z_{k}^{*}\left(x^{2}\right)$ \\
$\vdots$ & $\vdots$ & $\vdots$ & $\cdots$ & $\vdots$ \\
$x^{k}$ & $Z_{1}^{*}\left(x^{k}\right)$ & $Z_{2}^{*}\left(x^{k}\right)$ & $\cdots$ & $Z_{k}^{*}\left(x^{k}\right)$ \\
\hline
\end{tabular}

Step 3. Compute the lower bound $l_{i}$ and upper bound $u_{i}$ for each objective function as follows,

$$
\begin{aligned}
& u_{i}=\max \left\{z_{i}\left(x^{1}\right), \cdots, z_{i}\left(x^{k}\right)\right\} ; i=1, \cdots, k \\
& l_{i}=\min \left\{z_{i}\left(x^{1}\right), \cdots, z_{i}\left(x^{k}\right)\right\} ; i=1, \cdots, k
\end{aligned}
$$

Step 4. Define a membership function, for instance

$$
\mu\left(Z_{i}(x)\right)=\left\{\begin{array}{ccc}
0 & \text { if } & Z_{\mathrm{i}}(x) \geq u_{i} \\
d_{i}(x) & \text { if } & l_{i} \leq Z_{i} \leq u_{i} \\
1 & \text { if } & Z_{\mathrm{i}}(x) \leq l_{i}
\end{array}\right.
$$

where $d_{i}(x)=\frac{u_{i}-z_{i}}{u_{i}-l_{i}}$.

Step 4. Calculate $\beta_{i}$ as the ratio of ith objective function, which represent how far the ith objective is from the ideal value as follows,

$$
\beta_{i}=\min \left(\mu\left(Z_{1}\right), \cdots, \mu\left(Z_{k}\right)\right) \leq \mu\left(Z_{i}\right) .
$$

Therefore, we have,

$$
\max P=\sum_{i=1}^{k} w_{i} \cdot \beta_{i}
$$

subject to

$\beta_{i} \leq d_{i} ; i=1, \cdots, k$

$g_{j}(x) \leq b_{j} ; j=1, \cdots, m$

$$
\sum_{i=1}^{k} w_{i}=1
$$

$x_{i} \geq 0,0 \leq \beta_{i} \leq 1$

In problem (2), $\mathrm{P}=0$ means that the model could not reach its desirable value and $\mathrm{P}=1$ means it could reach its desirable value. 


\section{Case study}

The proposed model of this paper has been applied for a real-world case study of operating budgeting in city of Qom, Iran. There are different budgeting chapters and we need to rank them in terms of their relative importance. The proposed model uses analytical network process (ANP) for ranking various items. Saaty $(1999,2004)$ has introduced various kinds of ANP techniques, such as the Hamburger Model, the Car Purchase BCR model, and the National Missile Defense model. The proposed model of this paper applies a modified Feedback System model (Fig. 1) that permits inner dependences within the criteria cluster, where the looped are signifies the inner dependences.

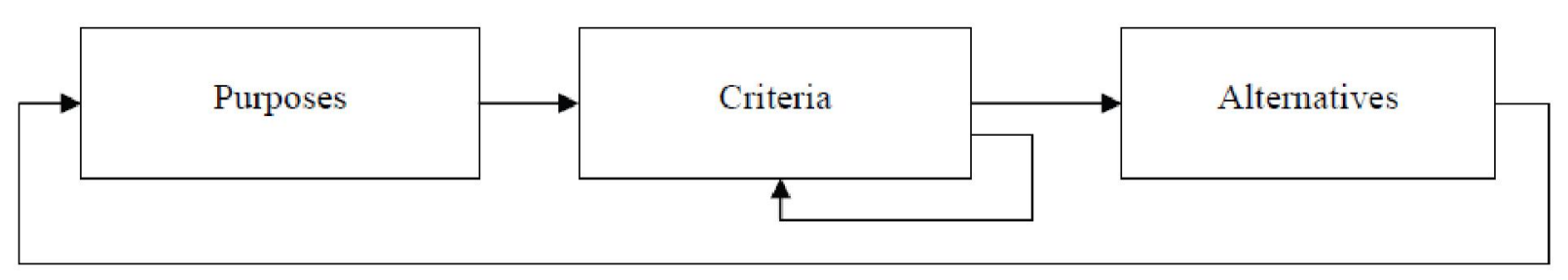

Fig.1. Feedback system model

To estimate the relative importance among various elements, all decision makers are invited to depend on a series of pair-wise comparisons and they are based on the Saaty's nine-point scale 1-9 and to evaluate the weights of elements. Table 2 demonstrates the results of our findings.

Table 2

The summary of ranking various budgeting chapters based on ANP method

\begin{tabular}{lclc}
\hline Chapter & Weight & Chapter & Weight \\
\hline General & 0.04981 & Sport & 0.063927 \\
Juridical & 0.041364 & Agriculture and natural resources & 0.065996 \\
Technical, financial & 0.010178 & Water resources & 0.058789 \\
Information technology & 0.030162 & Mining and industry & 0.059056 \\
Defence & 0.00674 & Environment & 0.033365 \\
Security & 0.007674 & Cooperation and trade & 0.058322 \\
Education & 0.021687 & Energy & 0.040038 \\
Art and Entertainment & 0.066263 & Transportation & 0.061792 \\
Healthcare & 0.102363 & Telecommunication & 0.039838 \\
Social security & 0.065862 & Real state & 0.116777 \\
\hline
\end{tabular}

Next, we are supposed to setup some targets and assign some values either deterministically or in terms of fuzzy numbers. Table 3 demonstrates the summary of our survey.

Table 3

The summary of targets for 20 different chapters

\begin{tabular}{|c|c|c|c|c|c|}
\hline Chapter & Nature & Goal & Chapter & Nature & Weight \\
\hline General & Deterministic & 15000 & Sport & Interval & $(68000-74000)$ \\
\hline Juridical & Deterministic & 52500 & Agriculture and natural resources & Fuzzy & $(58000-60000-62000)$ \\
\hline Technical, financial & Deterministic & 6150 & Water resources & Fuzzy & $(58000-60000-62000)$ \\
\hline Information technology & Deterministic & 22500 & Mining and industry & Fuzzy & $(140000-142500-145000)$ \\
\hline Defence & Deterministic & 7500 & Environment & Fuzzy & $(2000-2250-2500)$ \\
\hline Security & Interval & $(6000-9000)$ & Cooperation and trade & Fuzzy & $(1250-1500-1750)$ \\
\hline Education & Interval & $(200000-205000)$ & Energy & Fuzzy & $(700-750-800)$ \\
\hline Art and Entertainment & Interval & $(17000-18000)$ & Transportation & Fuzzy & $(80000-82500-85000)$ \\
\hline Healthcare & Interval & $(50000-60000)$ & Telecommunication & Fuzzy & $(14000-15000-16000)$ \\
\hline Social security & Interval & $(67000-68000)$ & Real state & Fuzzy & $(625000-630000-635000)$ \\
\hline
\end{tabular}


We have implemented the proposed model described earlier and Table 4 summarizes the results of our survey.

Table 4

The results of allocating different budgets by considering various alpha cut

\begin{tabular}{lccc}
\hline Chapter & $\alpha=0.25$ & $\alpha=0.50$ & $\alpha=0.75$ \\
\hline General & {$[10000,10000]$} & {$[10000,10000]$} & {$[10000,10000]$} \\
Juridical & {$[35000,40000]$} & {$[36000,38000]$} & {$[36000,37000]$} \\
Technical, financial & {$[4100,4100]$} & {$[4100,4100]$} & {$[4100,4100]$} \\
Information technology & {$[15000,22500]$} & {$[17000,20000]$} & {$[18000,19000]$} \\
Defence & {$[5000,5000]$} & {$[5000,5000]$} & {$[5000,5000]$} \\
Security & {$[5000,6000]$} & {$[5000,6000]$} & {$[5000,6000]$} \\
Education & {$[141130,200000]$} & {$[141630,200000]$} & {$[141930,200000]$} \\
Art and Entertainment & {$[12000,18000]$} & {$[13500,16500]$} & {$[15000,15000]$} \\
Healthcare & {$[50000,50000]$} & {$[50000,50000]$} & {$[50000,50000]$} \\
Social security & {$[40000,67000]$} & {$[40000,67000]$} & {$[40000,67000]$} \\
Sport & {$[48000,60000]$} & {$[50000,58000]$} & {$[52000,56000]$} \\
Agriculture and natural resources & {$[62351,55433]$} & {$[57348,61389]$} & {$[59226,60073]$} \\
Water resources & {$[59500,59500]$} & {$[59500,59500]$} & {$[59500,59500]$} \\
Mining and industry & {$[140000,141875]$} & {$[141000,142875]$} & {$[142000,143875]$} \\
Environment & {$[1500,1500]$} & {$[1500,1500]$} & {$[1500,1500]$} \\
Cooperation and trade & {$[1437,1437]$} & {$[1528,1528]$} & {$[1702,1702]$} \\
Energy & {$[400,800]$} & {$[450,750]$} & {$[500,700]$} \\
Transportation & {$[81875,81875]$} & {$[81875,81875]$} & {$[81875,81875]$} \\
Telecommunication & {$[1000,14000]$} & {$[1000,14000]$} & {$[1000,14000]$} \\
Real state & {$[628750,630650]$} & {$[629400,631700]$} & {$[630250,632850]$} \\
\hline
\end{tabular}

As we can observe from the results of Table 4, real state has received the highest operating budget followed by education, mining and industry. The results are presented in an interval forms so that it would give more flexibility for relocation of budget from one chapter into another one. This would help better management of budget and measuring the performance of various sectors, more accurately.

\section{Conclusion}

In this paper, we have presented an empirical investigation to assign appropriate budgets for various chapters in a real-world case study. The proposed study has applied interval data as well as fuzzy numbers to handle uncertainty in different chapters. Analytical network process has also been implemented to find appropriate weights for various chapters and using goal programming technique we have allocated desirable values in interval forms. The proposed model of this paper can be extended using other multi-criteria decision making such as Lp-norm, Lexicography, etc. and we leave it for interested researchers as future works.

\section{References}

Bourmistrov, A., \& Kaarbøe, K. (2013). From comfort to stretch zones: A field study of two multinational companies applying "beyond budgeting" ideas. Management Accounting Research, 24(3), 196-211

Guilding, C. (2003). Hotel owner/operator structures: implications for capital budgeting process. Management Accounting Research, 14(3), 179-199.

Ignizio, J. P. (1976). Goal programming and extensions (Vol. 26). Lexington, MA: Lexington Books.

Kalu, T.C.U. (1999). Capital budgeting under uncertainty: An extended goal programming approach. International Journal of Production Economics, 58(3), 235-251.

Lee, S. M. (1972). Goal programming for decision analysis (p. 387). Philadelphia: Auerbach.

Libby, T., \& Lindsay, R.M. (2010). Beyond budgeting or budgeting reconsidered? A survey of NorthAmerican budgeting practice. Management Accounting Research, 21(1), 56-75. 
Roper, A.H., \& Ruckes, M.E. (2012). Intertemporal capital budgeting. Journal of Banking \& Finance, 36(9), 2543-2551

Saaty, T. L. (1996). The analytic network process-decision making with dependence and feedback. Pittsburgh, PA: RWS Publications.

Saaty, T. L. (2004). Decision making - the analytic hierarchy and network processes (AHP/ANP). Journal of systems science and systems engineering, 13(1), 1-35.

Uyar, A., \& Bilgin, N. (2011). Budgeting practices in the Turkish hospitality industry: An exploratory survey in the Antalya region. International Journal of Hospitality Management, 30(2), 398-408

Zhang, Q., Huang, X., \& Tang, L. (2011). Optimal multinational capital budgeting under uncertainty. Computers \& Mathematics with Applications, 62(12), 4557-4567

Zimmermann, H.J. (1978). Fuzzy Programming and Linear Programming with Several Objective Function. Fuzzy Sets and Systems, 1(1), 45-55. 